\title{
A ESTÉTICA DO NEUTRO EM OZU E SUA ATUALIDADE ${ }^{1}$ Denilson Lopes Silva ${ }^{2}$
}

\begin{abstract}
Resumo: Este ensaio tem duas partes. Na primeira parte, tentamos ler a obra bastante conhecida de Yazujiro Ozu através do conceito do neutro de forma que o cotidiano e os seus personagens comuns possam ser uma forma de definir uma dramaturgia distinta, alternativa à tradição melodramática, hegemônica nas novelas e nos filmes hollywoodianos. Na segunda parte, tentaaos pensar $\mathrm{Ozu}$ a partir de filmes contemporâneos e tributos que foram feitos a sua obra.
\end{abstract}

Palavras-chave: Neutro. Ozu. Cotidiano

\begin{abstract}
This essay has two parts. At the first we try to read the widely known work of Yazujiro Ozu by the concept of neuter so that ordinary life and his ordinary characters should be a way of defining a different dramaturgy, alternative to the melodramatic tradition hegemonic at the television soap opera and movies done under the influence of Hollywood. At the second part, we try to think about Ozu through contemporary films and tributes done to his work.
\end{abstract}

Key-words: Neuter. Ozu. Ordinary Life.

"What the modern movie lacks is beauty, the beauty of moving wind in the trees, the little movement in a beautiful blowing on the blossoms in the trees. That they have forgotten entirely... In my arrogant belief, we have lost beauty"

D. W. Griffith em sua última entrevista

Partindo da proposta de um cinema-mundo, ou seja, não se trata de discutir apenas os efeitos da globalização no cinema ou pensar como o mundo é representado no cinema, mas como o cinema cria, reinventa um mundo, como ele pode criar uma comunidade de imagens,

\footnotetext{
${ }^{1}$ Uma versão reduzida deste texto foi apresentada XIII Encontro Anual da Sociedade Brasileira de Estudos de Cinema.

${ }^{2}$ Professor Adjunto da EScola de Comunicacao e Superintendente de Difusáo Cultural do Fórum de Ciëncia e Cultura da Universidade Federal do Rio de Janeiro, bolsista de produtividade científica do Conselho Nacional de Pesquisa (CNPq) Email: noslined@bighost.com.br.
} 
de pessoas dispersas, em vários lugares é que a questão do cotidiano e os filmes de Ozu nos vieram à mente.

Em meio às grandes questões políticas, econômicas, tecnológicas e sociais que emolduram o debate sobre a globalização, o cotidiano fica meio à sombra, quase imperceptível, nem espesso, nem transparente, nem espaço só de conservação do local, de tradições pré-modernas, nem só cena de sutil subversão, de reinvenção. Por onde caminham nossas vidas um dia após o outro, por onde elas se fazem ou se deixam fazer? Enfim, o que fazer da vida? Essas questões deixam de ser retóricas e grandiloquentes para ser algo mais modesto e que sempre volta: o que fazer no dia a dia?.

"O cotidiano não se deixa apanhar, pertence à insignificância, e o insignificante é sem verdade, sem realidade, sem segredo, mas é talvez também o lugar de toda significação possível. O cotidiano escapa. É nisso que ele é estranho, o familiar que se descobre (mas já se dissipa) sob a espécie do extraordinário" (Blanchot, 2007: 237).

Nada de oculto ou aventuroso, nem mesmo mais os dias de Stephen Dedalus em Ulysses de James Joyce ou de Clarissa em Mrs. Dalloway de Virginia Woolf. Se há mistério no cotidiano, ele não é nada metafísico, nem inconsciente, mas desse mundo, povoado por objetos e seres, entre os quais ocupamos um modesto lugar que só nossa vaidade cega e antropocêntrica nos faz colocar a nós mesmos numa posição central. Se há uma utopia nesse cotidiano é a busca do silêncio, do desaparecimento e da discrição, sem grandes saltos, passo a passo, momento a momento. Se há milagre é o acaso, o inesperado.

Para a difícil encenação desse familiar estranho no cinema é que apostamos uma vez mais na possibilidade de uma estética do cotidiano e do comum a ser conquistada, marcada pela delicadeza e pela leveza, distinta de valores como excesso, o grotesco, o abjeto, o cruel e mesmo o trágico. Na busca do cotidiano e do comum, apesar de e com todos os problemas, conflitos, confrontos que nos invadem, nos pesam, nos modificam, nos desafiam é que Ozu apareceu como um ponto de partida. Um outro cotidiano, um outro comum não só dilacerado por violências, mas também e sobretudo pela possibilidades de encontro, ao mesmo tempo, concreto, material, corpóreo e atravessado, ainda que muitas vezes, sutilmente, pelos fluxos informacionais e midiáticos.

Meu objetivo, portanto, não é vincular os filmes de Ozu a um debate sobre a cultura e cinema japoneses mas considerá-lo, num exercício de tradução cultural, uma ponta de lança para defender um cinema do cotidiano e do comum já proposto em outro momento (LOPES, 2007), especialmente centrado na casa, sem contudo lidar com a oposição privado/público, 
em que a maior intimidade pode estar não no vasculhamento de sentimentos e desejos supostamente ocultos e não revelados a não ser entre quadro paredes. Há um delicado sentimento de passagem do tempo, de nascimentos e mortes, e tantas outras pequenas perdas e transformações de que uma existência é feita, não tanto nostalgia de uma casa ou de família tradicionais nem demonização do espaço da cidade $^{3}$, como na postura serena do pai envelhecido que perdeu sua esposa ou cuja filha se casou e que se vê só na sua casa ${ }^{4}$ tanto em "Era uma vez em Tóquio"/ "Tokyo Story" (Tokyo Monogatari, 1953) como "Pai e Filha"/"Late Spring" (Banshun, 1949) que me fazem lembrar o encerramento de A Queda do Anjo, último livro de Mar da Fertilidade, tetralogia de Yukio Mishima (1988: 211):

"Era um jardim luminoso, tranqüilo, sem características marcantes. Como um rosário que se esfrega entre as mãos, o canto estrídulo das cigarras continuava predominando.

Não havia nenhum outro som. O jardim estava vazio. Honda refletiu que chegara a um lugar que não tinha nenhuma lembrança, não tinha nada.

O sol do meio-dia flutuava sobre o jardim imóvel."

Mesmo a viagem, ato de formação de uma subjetividade na tradição ocidental do Bildungroman, aparece rebaixada a algo mais prosaico em "Era uma Vez em Tóquio". A viagem que Shukichi (Chishu Ryu) e Tomi (Chieko Higashiyama), um casal de idosos, faz para ver seus filhos. Viagem marcada pelas dificuldades com que os filhos têm com a presença dos pais a ponto de Shukichi em tom meio irônico, meio melancólico se chamar de "homeless" (sem casa/sem lar), mas para logo depois, curiosamente, Tomi se sentir mais acolhida na pequena casa da nora, viúva do filho morto na Segunda Guerra Mundial, do que nas casas de seus filhos, ainda que brevemente. “A sensação de não ter lar (homelessness) não é sempre vivenciada como uma mutilação na vida, uma tristeza insuperável" (Jackson, 1995: 2). A casa enquanto lar, vem mais e mais deixando de ser um espaço fixo, uma base para uma relação social estável. A casa como a sensação de pertencimento são passagens, fluxos, momentos.

\footnotetext{
${ }^{3}$ Também não há uma ênfase na Tóquio moderna. A cidade aparece sem ênfase, o que Kiju Yoshida (2003: 182) chama de "Tóquio da invisibilidade". O predomínio é das imagens da intimidade ou de pequenas ruas, sem muitas pessoas o que ecoa nos filmes de Kore-eda e Kawase, que vão ainda mais longe, na encenação de seus dramas em pequenas cidades, sem que pareça uma recusa do contemporâneo, embora haja claramente um contraste com a Tóquio hipermoderna e dos mangás, espaço saturado pela luz de neon e por ícones pop (para uma leitura que enfatize a cultura massiva no Japão ver Iwabuchi, 2002), parecendo mais uma estratégia por uma outra temporalidade, um outro ritmo, uma outra forma de viver e perceber a vida, menos frenética e mais contemplativa, mas não sei se nostálgica, idealizadora de uma passado perdido.

${ }^{4}$ Talvez fosse interessante remeter ao belo registro da velhice feito por Vittorio de Sica em "Umberto D" (1952), contemporâneo de Ozu, este mais marcado pelo registro melodramático, para compreendermos mais a opção de Ozu.
} 
A maior intimidade, como nos aponta Ozu, pode estar não na sexualidade, cada vez mais hoje em dia, banalizada e espetacularizada, mas no compartilhamento de um momento, de uma imagem, de uma visão que pode ser roupas que balançam no varau, um trem que passa, o calor do sol, uma refeição em família ${ }^{5}$ ou uma conversa com amigos, sem nada a dizer de muito importante, a não ser não estar lá. Os chamados "pillow shots" (Burch, 1979: 160) ou planos de tempos mortos em que os objetos e espaços não ocupam um sentido muito explícito no desenrolar da ação não funcionam tanto como contextualização da cena, nem são apenas momentos de suspensão, paisagens ou naturezas-mortas a serem contempladas, eles apontam para um olhar que não é nem dos personagens mergulhados em sua interioridade nem do narrador onisciente, mas de "um olhar objetal ausente, invisível e caótico" (YOSHIDA, 2003, 196), de um olhar qualquer sem que os objetos e espaços adquiram demasiada autonomia nem a câmera se coloque em cena criando algum tipo de metalinguagem.

\section{"As coisas não precisam de você"}

\section{Antonio Cicero}

Na busca de sustentação de um drama desdramatizado é que chegamos a uma outra figura do comum, o neutro, não tanto como formulado por Blanchot ${ }^{6}$ mas por Barthes. $\mathrm{O}$ neutro vive um paradoxo como objeto é suspensão da violência e como desejo é violência (BARTHES, 2003, 30). O neutro não é tanto alvo, mas travessia (idem, 140), desejo. E o desejo de neutro é suspensão das ordens, leis, arrogância, exigências, do querer reter para si, como o pai em "Pai e Filha" que encena um envolvimento para que sua filha possa se casar, viver sua própria vida, não a reter narcisicamente, enquanto ele se dissolve na casa, no ocaso da sua velhice, em meio a algo que poderia ser uma dor ou tédio insustentáveis, mas como é momento a momento, torna-se quase invisível. Desapego mas não indiferença, "não é ausência, recusa do desejo, mas flutuação eventual do desejo fora do querer- agarrar" (idem, 34). Não a perda de si vista como angustiante alienação no mundo moderno, nem a integração pelo êxtase, pelo transe, pelo excesso, mas sutil e discreta dissolução, desaparecimento, eclipse, calma, não manifestação dos desejos mas eles estão presentes. O desafio do banal, de

\footnotetext{
${ }^{5}$ Ver análise comparativa entre cena de refeição em filmes de Ozu, Hou Hsiao-Hsen e Zhang Yimou (Bordwell, 2005: 186/188)

${ }^{6}$ Para uma discussão do neutro em Blanchot (Norditoli, 1995: 337/365), associada mais a um "apagamento da individualidade" (idem, 355) ou a um outro como radicalmente diferente (Levy, 2003: 42/4) que pode ser mais rentável para uma leitura das existências ásperas e empobrecidade em Beckett do que a existência mínima e delicada em Ozu.
} 
um dia após o outro, não o desafio do excesso, da desmesura, do grande feito, dos grandes acontecimentos.

Se compararmos os espaços vazios que pontuam os filmes de Ozu com os de Antonioni, em especial, os últimos momentos de "Eclipse" (1962) em que o espaço vazio final decorre da ausência dos amantes que combinaram se encontrar; o vazio em Ozu não fala da ausência da presença humana, de uma falta angustiante, mas o espaço e objetos quase se tornam protagonistas como os personagens que passam pela tela. É apenas um momento de escape ou de descentramento de uma lógica que se cristalizou desde a perspectiva renascentista, centrada no olhar humano, mas sem se perder no informe, no inumano que tanto interessa às experiências das vanguardas. Dizendo de outra forma, a maior intimidade pode estar numa vivência de exterioridades, não num mergulho no inconsciente, nas confissões, como vemos em tantos planos em que os personagens de Ozu estão lado a lado, ao invés da postura de campo e contracampo, de confronto direto. Os personagens são mais pontos no quadro do que o seu centro.

O neutro, portanto. seria a base de um drama desdramatizado, ao invés do conflito que move a ação, na esteira da poética aristotélica, ou de uma poética do excesso, na explosão dada-surrealista-artaudiana. Em Ozu, o diálogo não é o do olho no olho, das verdades a serem desenterradas e ditas, como nos filmes de Ingmar Bergman, O diálogo em Ozu é tanto com o espaço e objetos quanto com as pessoas que estão nele. Talvez seja dessa forma é que melhor devem ser aproveitadas, lidas a formalidade e polidez das relações pessoais nos filmes de Ozu, não como espaço de fingimento e repressão, mas associadas a um "estado fraco" (Barthes, 2003: 151), a uma "existência mínima" (idem: 157). Se a desdramatização a partir de Beckett e do Bresson de "Mouchette" seguem o caminho da aspereza, da secura, da rarefação que pode sufocar; em Ozu, a desdramatização, ainda pode ser preenchida por pequenos e breves momentos de beleza, num mundo empobrecido e marcado pelo trabalho e pelo tédio da rotina. Em Ozu o neutro remete não à indiferenciação, mas a sutis gradações de uma pintura abstrata monocromática.

\footnotetext{
"tanta coisa depende

de um

carrinho de mão

vermelho

esmaltado de água da

chuva
} 
ao lado das galinhas

brancas"

William Carlos Williams

Que Ozu, ao mesmo tempo tão distante e tão perto, é este que podemos ver em 2008 ? Não se trata de desconsiderar a história de sua recepção fora do Japão ${ }^{7}$. Diferente de Kurosawa e Mizoguchi que são consagrados em festivais europeus nos anos $50^{8}$, Ozu durante sua vida é conhecido praticamente só no Japão ou por um público vinculado à cultura japonesa $^{9}$, reconhecido como cineasta popular e clássico dentro do Japão desde 1932, gradualmente, após sua morte em 1963, é convertido fora do Japão em autor e uma alternativa ao cinema hollywoodiano, considerado como um "formalista rigoroso" (Hasumi, 1998: 116), um cineasta moderno, e diferentemente, dentro do Japão, foi criticado por cineastas da Nouvelle Vague japonesa como Nagisa Oshima e Shonei Imamura (Nygren, 2007: 148), tido como um cineasta conservador, tanto do ponto de vista formal como dos valores morais centrados na família.

Não me interessa prosseguir numa leitura que insiste nas suas marcas japonesas, desenvolvidas desde trabalhos clássicos como o de Donald Ritchie (1977) ou no interior da história do cinema japonês ${ }^{10}$, nem como o cineasta conservador criticado por Oshima e Imamura, mas talvez resgatar Ozu de uma outra forma: um cineasta obcecado pelo comum, pelo banal traduzido em frágeis dramas familiares muito bem redimensionados na bela

\footnotetext{
${ }^{7}$ Mitsushiro Yoshimoto (2000: 8) identifica três momentos de recepção do cinema japonês nos EUA: 1) celebração humanista de grandes autores e da cultura japonesa nos anos 60 , como no caso do trabalho pioneiro de Donald Ritchie; 2) celebração formalista e marxista do cinema japonês como uma alternativa para o cinema clássico de Hollywood nos anos 70; 3) reexaminação crítica das perspectivas anteriores através da introdução do discurso de alteridade e da análise intercultural dos anos 80.

${ }^{8}$ Akira Kurosawa tornou-se reconhecido internacionalmente ao ganhar o Leão de Ouro no Festival de Veneza por "Rashomon" em 1950 e Kenji Mizoguchi foi premiado sucessivamente no Festival de Veneza de 1952 a 1954, incluindo o Leão de Outro por "Contos da Lua Vaga" em 1953. Para a recepção de Ozu fora do Japão em comparação com outros cineastas japoneses (Desser, 1997: 2/3; Almas: 2008)

${ }^{9}$ De acordo com o historiador Jeffrey Lesser em entrevistas realizadas para a escrita de seu livro A Disconted Diaspora, filmes japoneses eram apresentados regularmente em várias salas de cinema na cidade de São Paulo, pelo menos já nos anos 50, e marcaram a memória de críticos como Rubem Biáfora bem como de cineastas como Walter Hugo Khouri. Há também uma entrevista de Carlos Reichenbach (in Hartog, 1985: 50-55) em que menciona importância de Ozu. Seria uma hipótese a ser confirmada se alguns cineastas e críticos brasileiros tiveram contato com o cinema de Ozu bem antes de seu reconhecimento na Europa e qual seu impacto. Mais recentemente, do ponto de vista de registro em livro, Ozu. O Extraordinário Cineasta do Cotidiano. Organizado por Lúcia Nagib e André Parente, publicado em 1990, é uma boa apresentação da obra do cineasta ao público brasileiro, mas não conta com nenhum artigo escrito por autores brasileiros. Seria interessante ainda consultar artigo de André Parente escrito sobre Ozu no seu livro Ensaios sobre o Cinema do Simulacro. Quanto à produção cinematográfica brasileira, apesar do elogio de Ozu feito em "Santiago" (2007) de João Moreira Salles, com direito à citação de trecho de filme de Ozu ou o uso de "planos mortos" em "A Casa de Alice" de Chico Teixeira, não aparecem ecoar um diálogo particular ou forte com com a proposta que defendemos neste ensaio.

${ }^{10}$ Para o contexto maior da história do cinema japonês, consultar Standish 2005 E Novielli, 2007.
} 
homenagem que Hou Hsiao Hsen ${ }^{11}$ fez a Ozu em "Café Lumière" (Kôhî jikô, 2003 ) bem como por cineasta japoneses contemporâneos como Hirokazu Kore-Eda ${ }^{12}$, especialmente em "Maboroshi no hikari" (1995), Naomi Kawase ${ }^{13}$, destacando seu filme de estréia "Moe no Suzaku"14 (1997), Jun Ichikawa, por exemplo, em "Tony Takitani” (2004). A recepção de Ozu, no Japão, após os anos 80 inclui desde novas avaliações críticas até mangás sobre sua vida (Kornes, 2007: 78). Não se trata tanto de mitificar a família convencional, mas encenar as classes médias (nem muito pobres nem muito ricos), sem idealizar seus valores, mas sem lhes tirar uma possibilidade de beleza e encantamento, sem cair "num estilo de cine New Age elegante, ilustrando lugares comuns confortáveis, brandos, quase místicos” (MARTIN, 2008, 52):

“Outra crítica feita a Ozu é de que seus filmes seriam irreais: cenários muito arrumados, composições bonitas demais. Para aqueles que só acreditam num realismo de 'boca do lixo', isto pode ser verdade: não se vêem favelas ou malandros que corrompem pessoas inocentes nos filmes de Ozu. Trata-se de um tipo diferente de realismo, que acredito muito superior" (Zeman, 1990: 125).

Me interessa pensar, para além do Japão, numa perspectiva comparativa e transcultural, este outro real, o cotidiano na sua materialidade, sem nenhuma pretensão alegorizante nem pelas marcas fortes da história, exemplificado pela maneira como a Segunda Guerra Mundial aparece em o clássico de Ozu - "Era uma vez em Tóquio" (1953), - sem ser sob a lógica do ressentimento, nem do trauma; mas simplesmente derivado da passagem do tempo, de continuar a viver. Talvez esta perspectiva nos abra uma outra possibilidade de transitar por seus filmes sem a referência a um estilo transcendental como o que Paul Schrader (1988) desenvolveu ao relacionar Ozu, Dreyer e Bresson.

Se os filmes, de caráter mais histórico, produziram uma imagem sobre o Japão de grande alcance, repletas de samurais e de um passado pré-moderno; ao mesmo tempo em que uma cultura massiva emergia e se desenvolvia no Japão; os filmes de Ozu alcançam um reconhecimento no circuito cinéfilo ocidental, que pode se inserir em uma outro estereótipo

\footnotetext{
${ }^{11}$ Para aproximações interessantes entre Hou Hsiao-Hsen e Ozu (Cadzyn, 2002: 222/3).

${ }^{12}$ Para o debate iniciado em torno de seu primeiro longa metragem de ficção, "Maboroshi" (1995), em especial, articulando a herança de Ozu com outros cineastas japoneses contemporâneo (Desser, 2007: 274/5). Neste contexto, "Maborosi" nos interessa por ser um drama que esvazia os momentos de maior intensidade pela elipse, por planos de paisagens e objetos, interpretações contidas, poucos closes e por enfatizar os atos banais do cotidiano.

${ }^{13}$ Para uma visão dos filmes da diretora (López, 2008).

${ }^{14}$ Sobre este filme, ver Mcdonald, 2006: 244/257.
} 
do Japão ${ }^{15}$ a partir do cotidiano pós-Segunda Guerra Mundial, como uma sociedade em que se moderniza economicamente ao mesmo que mantém suas tradições (com especial ênfase no vínculo como o Zen-Budismo).

Se a recepção de Ozu e seu papel na crítica já foi mapeada, gostaria de pensar um efeito-Ozu no cinema, a começar das homenagens explícitas que foram feitas a ele por Wim Wenders, Hou Hsiao-Hsen e Abbas Kiarostami, para depois dialogar com outros filmes contemporâneos. O que chamamos de efeito-Ozu pode ser uma possibilidade de manter ainda um cinema narrativo, clássico, que não se dissolve nas experiências radicais dos cinemas novos dos anos 60 , base para a proposta conciliatória do cinema pós-moderno que emerge com a crise da noção de vanguarda nos anos 70 .

Talvez menos o caminho da cinefilia e do simulacro que foi o que Wim Wenders percorreu, na busca de dar intensidade aos espaços urbanos marcados pelo consumo transnacional e pelo excesso de imagens midáticas, tão em sintonia, com muito do chamado cinema pós-moderno dos anos 80 , mas muito pelo que se poderia ser uma fragilidade diante de um modelo clássico narrativo, pela sua ausência de fortes momentos dramáticos, pela rarefação e pelo despojamento, de um cotidiano sem ornamentos (Erlich, 1997: 70) , que longe de tornar a narrativa seca e desprovida de afetos, de encenar uma ambiência familiar fortemente opressora, apenas a traduz sob o plano da sutileza e do detalhe em que espaços e objetos se tornam tão centrais quanto os personagens, diluindo e recolocando a intensidade emocional para além da voz, da palavra e da confissão.

Ozu poderia nos dar uma pista para um drama que não passe pelo trágico nem pelo melodramático mas também não pelo cotidiano marcado por um tempo saturado que se quer cada vez mais perto de um tempo real, com longos planos como em várias experiências do cinema underground dos anos 60 e que reaparece em vários autores contemporâneos tão diversos como Béla Tarr e Tsai Ming Liang. Um drama desdramatizado, sob o signo do neutro, a que já nos referimos, marcado por elipses mas que não chegam a quebrar a narrativa tradicional, mas não busca dar densidade psicológica aos personagens como no grande teatro naturalista do século XIX. Não há monólogos interiores. Os personagens falam só com os outros e as falas são contidas. Ao invés do excesso de ação ou de emoção, a ênfase está na ambiência e no tom (Desser, 1997: 10), nas pausas e silêncios que ecoam a tradição do drama

15 “ Por quê este cineasta que é o menos japonês foi considerado como tipicamente japonês?” (Hasumi, 1998: 10) 
Nô mas também o Impressionismo ${ }^{16}$ (Lopes, 2007), colocando em cena personagens comuns, nem épicos, nem trágicos, personagens medianos, com vidas medianas, nada de excepcionais nem heróicas, com falas convencionais sobre assuntos banais, sem nenhuma pretensão intelectual e poética, frases de efeito, reflexões abstratas e lições de vida, sujeitos em eclipse não por serem alienados, anônimos na multidão urbana como o homem moderno, mas figuras quase fantasmais, por marcarem pouco a sua presença, a sua voz, a sua vida, contudo sem nenhuma dimensão metafísica.

Mas para recuperar a experiência de desdramatização, do neutro em Ozu não se pode repetir, emular Ozu. Talvez esta tentação seja mais visível em "Tokyo Ga" de Wim Wenders (1985) ${ }^{17}$ ao buscar não só as imagens dos filmes de Ozu no Japão dos anos 80, mas iniciar e começar "seu" filme com cenas de "Era uma vez em Tóquio", falar com o cameraman de Ozu, filmar, usando as mesmas lentes que Ozu usava, nos mesmos lugares, e por fim, reencontrando e entrevistando um dos atores mais presentes na cinematografia de Ozu: Chishu Ryu. Wenders parte do cansaço das imagens midiáticas do presente para ser curado pelas imagens de Ozu, como o Trevor (Wiliam Hurt) é curado de sua cegueira pela personagem, não por acaso interpretado por Chishu Ryu em "Até o Fim do Mundo" ("Until the End of the World, 1991), outro filme de Wim Wenders.

O cansaço para Wenders (e talvez para o escritor e seu colaborador Peter Handke) é uma forma de ter acesso ao neutro. Fadiga, cansaço que não deve ser confundidos com depressão (Barthes, idem: 39), mas como uma forma de se "esvaziar" (idem: 37) e de expressão de um "direito ao repouso" (idem: 41) e talvez mais do que encontrar um pai, "seu único mestre", um antecessor a posteriori (já que Wenders toma contato com os filmes de Ozu só em 1973 (de acordo com Geist, 1983: 234), quando começava a escrever o roteiro de seu quarto longa-metragem, "Alice nas Cidades"/ "Alice in der Städten”, 1973), seja buscar nos filmes de Ozu uma casa, com o risco da nostalgia que acompanha o cinema de Wenders (2001, 221), como fica explícita na voz do próprio diretor: "Quanto mais a realidade de Tóquio aparecia como uma fantasmática, sem amor, ameaçante e mesmo inumana proliferação de imagens; maior e mais potente era a amorosamente organizada mítica cidade de Tóquio nos filmes de Yasujiro Ozu".

O cansaço e tédio como figuras do neutro podem ser encontrados também através da insônia que os protagonistas experimentam em "Encontros e Desencontros" ("Lost in

\footnotetext{
${ }^{16}$ A referência ao teatro Nô é comum, em se tratando de Ozu, mas não a referência ao Impressionismo. Ela aparece rapidamente mencionada (Zeman, 1999: 126) e procurei atualizá-la (Lopes, 2007: 169; Lopes, 1999: 79/81)

${ }^{17}$ Para uma leitura mais detalhada de "Tóquio Ga" de Wenders a partir da questão do simulacro (Alter, 1997)
} 
Translation”, 2003) de Sofia Coppola, devido à mudança de fuso horário na viagem dos EUA para o Japão e que possibilita o encontro deles num hotel em Tóquio, mas também do encontro deles com a cidade, sob uma perspectiva que se assume como intrusa, lida com os clichês mas vai além da dualidade opositiva entre Japão e Ocidente, entre o eu e o outro. O encontro é um breve momento na vida dos dois, enquanto a estrela do cinema norteamericano Bob Harris (Bill Murray) grava uma propaganda de whisky e Charlotte (Scarlet Johansson) espera seu namorado fotógrafo que está trabalhando. Eles estão de passagem em Tóquio e na vida um do outro. Há uma certa melancolia, enfatizada pela bem-escolhida música climática, mas nada dilacerante, nem no encontro nem no desencontro, que não remete a nenhum passado da cidade como no filme de Wenders, quase a nenhum passado dos protagonistas, como a nenhum futuro, apenas o presente fugaz e fantasmal que nos constitui.

Um contraponto com o filme de Sofia Coppola poderia ser tanto "Maborosi" de Koreeda como "Suzaku" de Naomie Kawase, por seus personagens acabarem por se situar em pequenas vilas: no filme de Koreeda, uma vila de pescadores; já no filme de Kawase, uma vila que vive na expectativa de construção de uma ferrovia, o que acaba não acontecendo. Se para a vila de pescadores, aparece para a protagonista, um espaço de reenício; a vila em Kawase não parece estar alheia ao processo de modernidade, mesmo que marcada pela sua marginalidade do processo, nada tão violento e brutal como a modernização encenada nas pequenas cidades chinesas, por exempo, em "Unknown Pleasures" (Ren xiao yao, 2002) de Jia Zhang-Ke. Tanto nos filmes de Kawase como nos de Koreeda, persiste um impalpável que pode ser apenas o vento que passa breve pelas árvores, como os encontros e desencontros, feitos por poucas palavras.

Se a homenagem de Wenders dialoga o cinema de Ozu com o cinema do simulacro; "Five Dedicated to Ozu" $" 18$ de Abbas Kiarostami (2003) parece levar o cinema de Ozu para um outro caminho, na esteira do cinema moderno, sem personagens individuais, apenas passantes pelos cinco longos planos fixos e sem cortes, equiparando no mesmo nível pessoas, objetos e animais em paisagens à beira-mar, num tempo saturado, presente desde as experiências do cinema underground norte-americano a trabalhos de vídeo arte.

Talvez a homenagem que mais me mobilize em nossa entrada no cinema contemporâneo seja "Café Lumière" de Hou Hsiao-Hsen, , filmado no Japão. Também como no caso de Wenders, Hou Hsiao-Hsen conhece os filmes de Ozu já no meio de sua carreira, e trilha um caminho particular no encontro com o cotidiano. Após fazer filmes mais comerciais

\footnotetext{
${ }^{18}$ Para uma leitura mais detalhada (Vieira, 2008)
} 
e traçar toda um vasto panorama da história de Taiwan, sempre relacionado com o cotidiano familiar, Hou Hsiao=Hsen, em filmes mais recentes, encena mais o contemporâneo, como em "Millenium Mambo" (“Qian xi man po", 2001), no próprio "Café Lumière”, num dos episódios de "Three Times" (“Zui hão de shi guang”, 2005) e em sua primeira produção feita na França, "Le Voyage du Ballon Rouge” (2007). A homenagem a Ozu não implica um pastiche, uma paráfrase mas um diálogo. Em “Café Lumière”, se a família tradicional é ainda forte nas decisões dos personagens, aqui a jovem solteira fica grávida, não quer se casar e este decisão é sugerida mais do que revelada dramaticamente. Mesmo na cena em que fala com os pais, este assunto parece ser tratado em pé de igualdade com outros assuntos mais corriqueiros. No fim do filme, os trens caminham como as várias possibilidades da vida e do cotidiano, igual e diferente a tantos outros dias, entre os muitos ou poucos dias que nós viveremos.

Por que (re)ver Ozu hoje em dia? Não como a sombra marcada pelo auto-controle e disciplina, mas pela possibilidade de trazer uma pouco de delicadeza em meio a um mundo de excessos de informação, falas, imagens e sons, por um desejo de uma vida mais comum mas não menos bela. Uma questão que ainda nos fica e insiste a partir de Ozu é de como mostrar a casa diante da exploração máxima da intimidade, da espetacularização dos afetos e dos reality shows? Que casa é essa que pode nos acolher? Terminamos nossa viagem pelo comum voltando às mesmas questões com que começamos nossa caminhada. O pudor que nos vem a partir de Ozu reaparece não como forma de silenciar e reprimir afetos, mas de revalorizar a sutileza e a invisibilidade dessa casa que começava a se dispersar nos seus filmes. Fica talvez ainda o desejo de reconstruir, reconquistar uma sensação de estar em casa no mundo, "uma experiência de completa consonância entre o nosso corpo e o corpo da Terra. Entre eu e o outro. Não importa se o outro é uma paisagem, algo ou alguém amado, uma casa ou um ato. As coisas fluem. Parece não haver resistência entre eu e o mundo. A relação é tudo." (Jackson, 1995: 110).

\section{Referências bibliográficas}

BARTHES, R. Mitologias. São Paulo: Difel, 1987.

BARTHES, R. Retórica antiga. In: COHEN, J. [et alii]. Pesquisas de retórica. Petrópolis: Vozes, 1975.

ALMAS, A. Japão de Brasileiros: O Cinema Japonês e sua Inter-Imagem no Cinema Brasileiro In: GREINER, C. e FERNANDES, R. (orgs.). Tokyogaqui: um Japão Imaginado. São Paulo: SESC SP, 2008. 
ALTER, N. Documentary as Simulacrum: Tokyo-Ga In:COOK, R. e GEMÜNDEN, G. (orgs.). The Cinema of Wim Wenders. Detroit: Wayne State University Press, 1997.

BARTHES, R. O Neutro. São Paulo: Martins Fontes, 2003.

BLANCHOT, M. A Conversa Infinita 2: A Experiência Limite. São Paulo: Escuta, 2007.

BORDWELL, D. Hou, or Constraints In: Figures Traced in Light: On Cinematic Staging. Berkeley: University of California Press, 2005.

BURCH, N. To The Distant Observer. Forms and Meanings in Japanese Cinema. Berkeley: University of California Press, 1979.

CADZYN, E. The Flash of Capital. Filme and Geopolitics in Japan. Durhan: Duke University Press, 2002.

DESSER, D. Introduction In: DESSER, D. (org.) Ozu's Tokyo Story. Cambridge: Cambridge University Press, 1997. . The Imagination of the Transcendent In: PHILIPS, A. e STRINGER, J. (orgs.).Op. cit. 2007.ERLICH, L. Travel Toward and Away In: DESSER, D. (org.). Ozu's Tokyo Story. Cambridge: Cambridge University Press, 1997.

. New View, New Choices In: Viennale Retrospective. Viena, 2004.

FISCHER, S. Azuis de Ozu e de Aïnouz: Clausura e Deslocamento, Paper apresentado no XII Encontro Internacional da Socine, Brasília: UnB, 2008.

GEIST, K. "West looks East: The Influence of Yasujiro Ozu on Wim Wenders and Peter Handke" In: Art Journal, V. 43, n.3, outono 1983.

HARTOG, S. "Interview with Carlos Reichembach for the television program Visions", Framework: The Journal of Cinema and Media, 28,1985.

HASUMI, S. Yasujiro Ozu. Paris: Editions de l'Étoile/Cahiers du Cinéma, 1998.

IWABUCHI, K. Recentering Globalization.Popular Culture and Japanese Transnationalism.

Durham: Duke University Press, 2002.

JACKSON, M. At Home in the World. Durham: Duke University Press, 1995.

KORNES, A. The Riddle of the Vase: Ozu Yasujiro's Late Spring (1949) In: PHILIPS, A. e STRINGER, J. (orgs.). Op. Cit.

LARDín, R, e NAVARRO, J. (orgs.). El Principo del Fin. Tendências y Efectivos del Novíssimo Cine. Madri> Paidós/Sitges/The Japan Foundation, 2003.

LÉVY, T. A Experiência do Fora: Blanchot, Foucault e Deleuze. Rio de Janeiro, RelumeDumará: 2003.

LOPES, D. Nós os Mortos: Melancolia e Neo-Barroco. Rio de Janeiro: 7Letras, 1999. . A Delicadeza: Estética, Experiência e Paisagens. Brasília: Ed.UnB, 2007. 
LÓPEZ, J, (org.). Naomi Kawase. El Cine em el Umbral. Madri: T \& B/Festival Internacional de Cine Las Palmas de Gran Canária/CGAI, 2008.

LOVE, M. Café Lumière In: FRODON, J. (org.). Hou Hsiao-Hsen. Paris, Cahiers du Cinéma: 2005.

MARTIN, A. Cierto Oscuro Rincón del Cine Moderno In: LÓPEZ, J. (org.). Op. cit. 2008.

McDONALD, K. Reading a Japanese Film. Honolulu: University of Hawai'i Press, 2006.

MISHIMA, Y. A Queda do Anjo. São Paulo: Brasilense, 1988.

NAGIB, L. e PARENTE, A. (orgs.). Ozu: o Extraordinário Cineasta do Cotidiano. São Paulo: Marco Zero/Cinemateca Brasileira/Aliança Cultural Brasil-Japão, 1990.

NORDITOLI, A. Um Éthique de l'Écriture In: Maurice Blanchot. L'Écriture comme Expérience du Dehors. Toulouse: Droz, 1995.

NOVIELLI, M. História do Cinema Japonês. Brasília: Ed.Unb, 2007.

NYGREN, S. Time Frames. Japanese Cinema and the Unfolding of History. Minneapolis: University of Minnesota Press, 2007.

PARENTE, A. Ensaios sobre o Cinema do Simulacro. Rio de Janeiro: Pazulin, 1998.

PHILIPS, A. e STRINGER, J. (orgs.). Japanese Cinema: Texts and Contexts. New York: Routledge, 2007.RITCHIE, D. Ozu. Berkeley: University of California Press, 1977. - Retratos Japoneses.Crônicas da Vida Pública e Privada. São Paulo: Escrituras/Ed.Unesp, 2000.

SCHRADER, P. Transcendental Style In:Film: Ozu, Bresson, Dreyer. Da Capo, 1988.

STANDISH, I. A New History of Japanese Cinema. A Century of Narrative Cinema. New York/Londres: Continuum, 2005.

VIEIRA, J. "Quem sou eu? Cinema japonês contemporâneo e a identidade em xeque”, In: Poesia Sempre, ano X, n.17 (dezembro 2002), Rio de Janeiro, Biblioteca Nacional.

VIEIRA, E. O tempo da pintura videográfica: Reflexões sobre os Usos do Plano-seqüência em Cinco, de Abbas Kiarostami. Mimeo, 2008.

YOSHIDA, K. O Anticinema de Yasujiro Ozu. São Paulo: Cosac \& Naify, 2003.

YOSHIMOTO, M. Japanese Cinema in Search of a Discipline In: Kurosawa. Film Studies and Japanese Cinema. Durham: Duke University Press, 2000.

WENDERS, W. Tokyo-Ga In: On Films: Essays and Conversations. New York: Faber \& Faber, 2001.

ZEMAN, M. A Arte Zen de Yasujiro Ozu, o Poeta Sereno do Cinema Japonês In: NAGIB, L. e PARENTE, A. (orgs.). Op. cit.. 